\title{
Suppression Subtractive Hybridization and Differential Screening Reveals Endodormancy-associated Expression of an $S V P / A G L 24$-type MADS-box Gene in Lateral Vegetative Buds of Japanese Apricot
}

\author{
Hisayo Yamane ${ }^{1}$, Yukinobu Kashiwa, Tomomi Ooka, Ryutaro Tao, and Keizo Yonemori \\ Laboratory of Pomology, Graduate School of Agriculture, Kyoto University, Kyoto 606-8502, Japan
}

AdDitional Index words. MIKC-type MADS-box gene, Prunus mume, StMADS11

\begin{abstract}
To understand the molecular basis of the endodormancy of buds of perennial plants, we searched for the genes that are expressed preferentially in endodormant lateral buds of the deciduous fruit tree japanese apricot (Prunus mume Sieb. et Zucc.) using suppression subtractive hybridization with mirror orientation selection (SSH/ MOS). We generated two SSH/MOS libraries containing gene pools that are expressed preferentially in endodormant buds in comparison with paradormant or ecodormant buds to search for the genes that are upregulated by endodormancy induction or down-regulated by endodormancy release, respectively. Differential screening and sequencing indicated that genes involved in gibberellin metabolism, stress resistance, cell wall modification, and signal transduction, such as transcription factors, are upregulated in endodormant buds. After a further expression survey and full-length cDNA cloning, we found that a gene similar to the $S V P / A G L 24$-type MADS-box transcription factor showed endodormancy-associated expression. Seasonal expression analysis suggested that the $S V P / A G L 24$ homolog in japanese apricot might be involved in endodormancy regulation of its lateral buds.
\end{abstract}

Bud dormancy allows perennial plants of temperate and boreal zones to survive low winter temperatures. Lateral buds are formed in early summer and enter a paradormant state caused mainly by apical dominance. By mid to late autumn, with the exact timing depending on the species, the inhibitory control of bud growth shifts to the bud itself; these buds are referred to as being endodormant (Lang, 1987). Plants are incapable of emerging from this type of dormancy by the removal of terminal buds or defoliation. Endodormant buds require a certain amount of chilling accumulation for the transition to an ecodormant state from which buds are capable of resuming growth in favorable environments (Crabbe and Barnola, 1996; Faust et al., 1997). In contrast to endodormancy, ecodormancy is imposed by external environmental factors such as cold or drought stress, which induce critical signals that prevent bud growth (Crabbe and Barnola, 1996; Horvath et al., 2003; Lang, 1987).

Endodormancy is the result of physiological changes in response to an internal signal that inhibits continuous rapid growth toward budbreak. Certain signals that mediate the induction of endodormancy have been identified and characterized. The role of plant hormones in endodormancy, especially abscisic acid (ABA), is well established. The ABA level is increased in dormant buds during cold and drought stress. Poplars (Populus tremula L. var. sieboldii Miq. $\times$ P. alba L.) that overexpress ABSCISIC ACID INSENSITIVE 3 (ABI3) do not form terminal buds, suggesting that ABA affects dormancy acquisition (Rohde and Bhalerao, 2007; Rohde et al., 2002).

Received for publication 10 June 2008. Accepted for publication 30 June 2008. This work was supported in part by Grants in Aid 19780020 for Young Scientists (B) to H.Y. from the Japan Society for the Promotion of Science.

${ }^{1}$ Corresponding author. E-mail: hyamane@kais.kyoto-u.ac.jp.
Although a complex set of overlapping hormonal signals is responsive to various environmental and physiological conditions related to dormancy (for review, see Horvath et al., 2003; Rohde and Bhalerao, 2007), how the signals are involved in dormancy remains to be elucidated. In contrast to the extensive study of the physiology of dormancy break, the internal factors controlling endodormancy are poorly understood. For stable deciduous fruit production, uniform flowering is important, but has not been achieved recently in protected cultivation in Japan because of irregular lateral bud endodormancy release, putatively caused by global warming (Sugiura et al., 2007). This led us to search for genetic factors controlling endodormancy, with the goal of helping to recover uniform flowering of deciduous fruit tree species in Japan.

Studies using genetic and molecular approaches to understand the mechanisms that regulate bud endodormancy and dormancy release are ongoing for various plant species (for review, see Rohde and Bhalerao, 2007). Some of the quantitative trait loci (QTLs) that regulate dormancy in potato (Solanum tuberosum L.) and poplar (Populus trichocarpa Torr. \& A. Gray) are associated with ABA content or signaling and photoperiod perception. Considerable efforts to identify the genes associated with dormancy have been made using the transcriptome approach in grape (Vitis vinifera L.) (Pacey-Miller et al., 2003), raspberry (Rubus idaeus L.) (Mazzitelli et al., 2007), poplar ( $P$. tremula $\times P$. alba) (Rohde et al., 2007; Ruttink et al., 2007), and leafy spurge (Euphorbia esula L.) (Jia et al., 2006). Endogenous processes that induce growth cessation and terminal bud set have been partly characterized. Böhlenius et al. (2006) suggested that $C O$ (CONSTANS) and FT (FLOWERING LOCUS T), which are flowering regulators in arabidopsis [Arabidopsis thaliana $(\mathrm{L}$. 
Heynh.] are involved in short-day-induced seasonal growth cessation of $P$. trichocarpa. In addition, Bielenberg et al. (2008) identified MADS-box genes as candidate genes associated with terminal bud formation of peach [Prunus persica (L.) Batsch]. However, thus far, genes that are directly involved in lateral bud endodormancy regulation have not been identified.

We performed suppression subtractive hybridization supplemented with mirror orientation selection (SSH/MOS) and differential screening to identify genes that are expressed preferentially in endodormant buds of japanese apricot. This species of fruit tree was selected for study because its seasonal endodormancy status has been well characterized (Takamatsu et al., 2004; Yamane et al., 2006). Also, its relatively low chilling requirement for budbreak, and resultant early flowering, often causes unstable fruit yield because a large number of flowers abort due to lack of pollination and fertilization. This occurs because pollinators (bees) tend to be inactive in early spring, or may be attributable to the late spring frost (Miyahara and Tomita, 1982). Thus, delayed flowering time of japanese apricot is required by means of controlling endodormancy release or controlling flower organ development in the ecodormant stage. Accumulating knowledge of endodormancy regulation would enable us to control endodormancy through cultural procedures or breeding.

To search for genetic factors controlling endodormancy, we generated two subtraction libraries. First, we generated a SSH/ MOS library containing gene pools that are expressed preferentially in endodormant buds compared with ecodormant buds to search for genes that are down-regulated by endodormancy release. Second, we generated a SSH/MOS library containing gene pools that are expressed preferentially in endodormant buds compared with paradormant buds to search for genes that are upregulated by endodormancy induction. We especially intended to isolate the genes specifically expressed in endodormant buds among paradormant, endodormant, and ecodormant buds. Endodormant buds are different from other dormant buds (paradormant and ecodormant buds) in that they are not able to resume growth under favorable conditions, which suggests that internal factors inhibiting bud burst and growth should be present in endodormant buds and absent in paradormant and ecodormant buds. In addition, the genes expressed specifically in endodormant buds compared with nonendodormant buds may function downstream of the endodormancy-regulation pathway after perception and transduction of the signals that induce endodormancy and endodormancy break. Thus, to search for genes that are highly upregulated in endodormant buds compared with paradormant and ecodormant buds, we conducted additional differential screening. As a result, we obtained a MADS-box gene that shows endodormancy-associated expression. Seasonal expression analysis suggested that the MADS-box gene was upregulated during endodormancy induction and down-regulated during endodormancy release. Fulllength cDNA cloning of this gene and phylogenic analysis revealed that it was similar to SVP/AGL24 type MADS-box genes of arabidopsis. We discuss the biological function of the MADS-box gene with special references to its sequence similarity to the $S V P / A G L 24$-type MADS-box genes.

\section{Materials and Methods}

Plant materials. We used field-grown trees ( 7 years after grafting and 6 years after transplanting, seed-grafted) and 16 pot-grown trees (3 years after grafting, seed-grafted) of the japanese apricot cultivar Nanko. The trees were grown at the Kyoto University experimental farm, Kyoto, Japan (lat. $34^{\circ} \mathrm{N}$, long. $135^{\circ} \mathrm{E}$ ). Although japanese apricot forms flower buds and vegetative buds as lateral buds, we used only vegetative buds. Both bud types exhibit endodormancy and require chilling exposure for endodormancy release, whereas flower organ development occurs during endodormancy (Takamatsu et al., 2004). We assumed that chilling accumulation promotes endodormancy release, as well as flower organ development, suggesting potential difficulties in distinguishing the genes that are related to endodormancy from those that are related to flower organ development if flower buds were studied. In contrast, vegetative buds do not show visible differentiation during the endodormant stage (Takamatsu et al., 2004), indicating that these organs could be used effectively for the study of endodormancy.

From late Oct. 2005 [0 chilling hours $(\mathrm{CH})$; i.e., below $7.2{ }^{\circ} \mathrm{C}$ ] to the beginning of Mar. $2006(>1400 \mathrm{CH}), 10$ potgrown 'Nanko' trees were placed in a greenhouse and maintained at $15{ }^{\circ} \mathrm{C}$ to $20{ }^{\circ} \mathrm{C}$ under natural daylengths to prevent chilling exposure, which promotes endodormancy release. In Mar. 2006, lateral vegetative buds were collected from the potgrown trees, as well as from field-grown trees. The buds derived from pot-grown trees were used as endodormant buds, whereas those from field-grown trees were used as ecodormant buds because 'Nanko' vegetative buds require more than $\approx 1000 \mathrm{CH}$ to completely break endodormancy (data not shown). If endodormant and paradormant buds were collected under similar environmental conditions, effects derived from factors unrelated to endodormancy could be excluded; however, none of the artificial treatments prevented paradormant buds from progressing into endodormancy. Thus, lateral buds were collected in June 2006 ( 2 months after leaf flush) and were used as paradormant buds, whereas lateral buds collected in Oct. 2006 were used as endodormant buds. Bud burst of potgrown trees was observed within $10 \mathrm{~d}$ after being defoliated and decapitated in June, as described below, indicating that the lateral buds in June were not endodormant. For seasonal expression analysis, lateral vegetative buds of field-grown 'Nanko' trees were collected monthly from June to March. The collected buds were immediately frozen in liquid nitrogen and stored at $-80{ }^{\circ} \mathrm{C}$ until use.

RNA EXTRACTION AND SSH/MOS. Total RNA was isolated from buds using the CTAB method following Yamane et al. (2006). The cDNA was synthesized from RNA extracted from paradormant, endodormant, and ecodormant buds using the SMART PCR cDNA Synthesis Kit (Clontech; TaKaRa Bio, Shiga, Japan) according to the manufacturer's instructions. Two PCR-Select subtractive libraries were constructed using the Clontech PCR-Select cDNA Subtraction Kit (TaKaRa Bio) following the manufacturer's instructions. SSH library 1 contained the genes that were expressed in endodormant buds (collected in Mar. 2006 from the pot-grown trees in the greenhouse) minus the genes that were expressed in ecodormant buds (collected in Mar. 2006 from the field-grown trees). SSH library 2 contained the genes that were expressed in endodormant buds (collected in Oct. 2006 from the field-grown trees) minus the genes that were expressed in paradormant buds (collected in June 2006 from the field-grown trees). The MOS technique was used to eliminate false-positive clones from SSH libraries following the methods of Rebrikov et al. (2000). In 
brief, the subtracted cDNA pools were digested by XmaI, denatured at $98^{\circ} \mathrm{C}$ for $1.5 \mathrm{~min}$, and incubated at $68^{\circ} \mathrm{C}$ for $3 \mathrm{~h}$ to allow hybridization of each mirror-oriented molecule. The hybridized samples were used for subsequent polymerase chain reaction (PCR). The PCR mixtures and conditions were identical to those used by Rebrikov et al. (2000). The PCR products were cloned using a pGEM-T Easy TA Cloning Kit (Promega, Madison, WI).

DIFFERENTIAL SCREENING BY DOT-BLOT HYBRIDIZATION AND VIRTUAL NORTHERN BLOT HYBRIDIZATION. Differential screening was performed according to the manufacturer's instructions (Clontech). In brief, randomly selected clones from SSH/MOS library 1 were grown overnight on a shaker. A $1-\mu \mathrm{L}$ aliquot of the bacterial culture was used for PCR using the NP2Rs primer (5'-GGTCGCGGCCGAGGT-3'). The PCR products were spotted on nylon membrane (Biodyne PLUS; Pall Corp., Pensacola, FL). Hybridization was performed using DIGlabeled subtracted cDNA from forward (endodormant minus ecodormant) or reverse (ecodormant minus endodormant) subtractions (XmaI-treated secondary PCR products) using the PCR DIG Probe Synthesis Kit (Roche Diagnostics, Mannheim, Germany) with NP2Rs primer. For probe preparation, PCR was performed using initial denaturation at $94{ }^{\circ} \mathrm{C}$ for $2 \mathrm{~min}, 23$ cycles at $94{ }^{\circ} \mathrm{C}$ for $20 \mathrm{~s}, 62^{\circ} \mathrm{C}$ for $20 \mathrm{~s}$, and $72{ }^{\circ} \mathrm{C}$ for $1.5 \mathrm{~min}$; and a final extension at $72{ }^{\circ} \mathrm{C}$ for $7 \mathrm{~min}$. After dot-blot hybridization in hybridization buffer $(4 \%$ skim milk, $5 \times$ SSC, $0.1 \%$ sodium lauroylsarcosin, $0.02 \%$ SDS, and $20 \mu \mathrm{M}$ NP2Rs primer) at $72{ }^{\circ} \mathrm{C}$, the membrane was washed four times in $2 \times \mathrm{SSC}, 0.1 \% \mathrm{SDS}$ for $20 \mathrm{~min}$ at $72^{\circ} \mathrm{C}$ and twice in $0.1 \times$ $\mathrm{SSC}, 0.1 \% \mathrm{SDS}$ for $20 \mathrm{~min}$ at $72{ }^{\circ} \mathrm{C}$. Immunological detection of hybridized nucleic acids was carried out using the anti-DIGalkaline phosphate conjugate and the chemiluminescent substrate CDP-star (New England Biolabs, Beverly, MA). Chemiluminescence was documented on X-ray film. From SSH/MOS library 1, $1488 \mathrm{SSH} / \mathrm{MOS}$ clones were subjected to dot-blot hybridization screening. In total, 432 clones were differentially expressed between the two gene pools. The nucleotide sequences of randomly selected clones were determined using the CEQ8000 and DTCS Quick Start Master Mix (Beckman Coulter, Fullerton, CA). Contig and sequence analysis were carried out using ATGC software (Genetyx, Tokyo). The remaining clones were then subjected to dot-blot screening to eliminate the same clones from the already sequenced clones. As a result, 33 different clones were obtained. Similarly, 132 clones from SSH/MOS library 2 were randomly selected and sequenced. In total, 70 different clones were isolated. Thirtythree and 70 different clones from libraries 1 and 2, respectively, were then subjected to virtual northern blot hybridization to determine the differential expression among the three dormant bud stages: paradormant, endodormant, and ecodormant. Virtual northern blot analysis was performed according to the manufacturer's instructions (Clontech). In brief, $500 \mathrm{ng}$ of cDNA synthesized using the SMART PCR cDNA Synthesis Kit from endodormant (collected in Oct. 2006), ecodormant, and paradormant buds were run in formaldehyde (1\%) agarose gel, blotted onto nylon membrane, and probed by the DIG-labeled selected SSH/MOS clones. Hybridization and detection were carried out as described above. The functional annotation of sequences was predicted based on similarities to previously identified sequences obtained by searching two public databases [DNA Data Bank of Japan (DDBJ) and National Center for Biological Information
(NCBI)] using the BLASTX tool for deduced amino acid sequences. E-values $>0.01$ were considered not significant (i.e., no match). The pfam search results were also considered for annotation.

SEasonal dormancy STATUS OF 'NANKo' Vegetative BUdS. The timing of endodormancy induction and endodormancy release of 'Nanko' vegetative buds was investigated in the middle of each month. In summer, from June to August, two pot-grown trees in the field were defoliated and decapitated monthly. Days to bud burst of at least two buds per tree were counted. In autumn to early spring, from September to March, monthly dormancy status was investigated using cut branches. In brief, three branches with lengths of $\approx 50 \mathrm{~cm}$ were cut from trees and divided into five parts each. The triplicates of three branch parts derived from middle portions of five branch parts were used. A total of nine branch parts, bearing two to three buds each, were placed in water in a growth chamber and were maintained at $25{ }^{\circ} \mathrm{C}$ under cool white fluorescent light and a 16-h photoperiod. After 3 weeks in the chamber, buds showing green leaves were considered to have burst. In total, 15 to 18 buds, located in the top portions of the branch parts, were counted.

RNA BLOT ANALYSIS. The seasonal expression pattern of the clone obtained from the SSH/MOS library was investigated by RNA blot analysis. Total RNA was isolated from 'Nanko' vegetative buds, collected monthly, as described above. We ran $5 \mu \mathrm{g}$ of the total RNA in a formaldehyde (1\%) agarose gel, blotted it onto a nylon membrane, and probed it with a partial cDNA sequence of the SSH/MOS clone labeled by DIG-dUTP. The membrane was hybridized at $65^{\circ} \mathrm{C}$ overnight and washed, and signals were detected as described above.

CDNA LIBRARY CONSTRUCTION AND SCREENING. Total RNA isolated from endodormant buds of field-grown 'Nanko' collected in October was used to construct a cDNA library following the instruction manual (SMART cDNA library construction kit, Clontech). Poly(A $)^{+}$RNA was isolated from the total RNA using Oligo-dT cellulose (Wako, Osaka, Japan). Using the first-strand cDNAs synthesized from $\approx 0.2 \mu \mathrm{g}$ of poly $(\mathrm{A})^{+}$RNA, cDNAs were amplified by long-distance PCR with Advantage 2 polymerase, cloned into $\lambda$ TriplEx 2 vector (Clontech), and packaged in vitro using MaxPlax Packaging Extract Kit (Epicentre Technologies, Madison, WI). Five thousand plaques were screened by plaque hybridization using the DIG-labeled SSH/MOS clone as a probe. After the low stringency washes $(2 \times 5 \mathrm{~min}$ at room temperature with $5 \times \mathrm{SSC}$ and $0.1 \%$ SDS followed by $2 \times 15 \mathrm{~min}$ at $68{ }^{\circ} \mathrm{C}$ with $1 \times \mathrm{SSC}$ and $0.1 \%$ SDS), colorimetric detection with nitroblue tetrazolium (Nacalai Tesque, Kyoto, Japan) and 5-bromo-4-chloro3-indolyl phosphate (Nacalai Tesque) was conducted as described in Tao et al. (1999). Selected clones were converted to pTriplEx2 plasmids according to the instruction manual (Clontech), and nucleotide sequences were determined as described above.

Construction of a PHYlogenetic TREe. The full-length deduced amino acid sequences of 38 genes belonging to the MIKC-type MADS-box transcription factor gene family in arabidopsis (Pařenicová et al., 2003) and the gene identified in this study were used to construct a phylogenetic tree. After the amino acid sequences were aligned using CLUSTAL X, the phylogenetic tree was constructed by the neighbor-joining method and displayed with the MEGA4 software package (Tamura et al., 2007). 


\section{Results and Discussion}

SSH/MOS LIBRARY SCREENING, SEQUENCING, AND ANNOTATION. To elucidate the endodormancy regulation in japanese apricot, we sought to isolate the genes preferentially expressed in endodormant buds compared with the paradormant and ecodormant stages of buds. For this purpose, we constructed two different SSH/MOS libraries containing cDNA clones that were expressed in endodormant buds minus those that were expressed in ecodormant (library 1) or paradormant (library 2) buds. After extensive screening, a total of 7 and 19 clones from SSH/MOS libraries 1 and 2, respectively, exhibited a more than 3 -fold increase in intensity in endodormant buds compared with ecodormant or paradormant buds (Fig. 1) when analyzed by virtual northern blot analysis. BLAST search results are shown in Table 1. Of the obtained clones, only one was isolated as a common clone in the two libraries (Table 1); it was similar to the MADS-box transcription factor Ppdam6 (Prunus persica dormancy-associated MADS6; DDBJ/ EMBL/GenBank accession number DQ863252; Bielenberg et al., 2008). Clones that were similar to database-registered cytochrome P450 monooxygenase were also included in both libraries; however, the clone from library 1 was considered to differ from that in library 2 because their sequences had very low similarity (data not shown). Seasonal gene expression changes in buds of raspberry (Mazzitelli et al., 2007) and leafy spurge (Jia et al., 2006) were investigated using microarray analysis. Both of these studies indicated that cytochrome P450 monooxygenase was preferentially expressed in endodormant buds, which is in agreement with our results.

Most clones showed preferential expression in paradormant and endodormant buds (Fig. 1B) or in endodormant and ecodormant buds (Fig. 1C), suggesting that distinct genes are involved in endodormancy induction or endodormancy release. The clones down-regulated in ecodormant buds compared with endodormant buds include gibberellin 2 Table 1). oxidase (GA2ox; Table 1). Several reports have suggested critical roles of gibberellins (GAs), which promote progression from dormancy release, in acting downstream of environmental signals to regulate bud dormancy (Crabbe and Barnola, 1996;
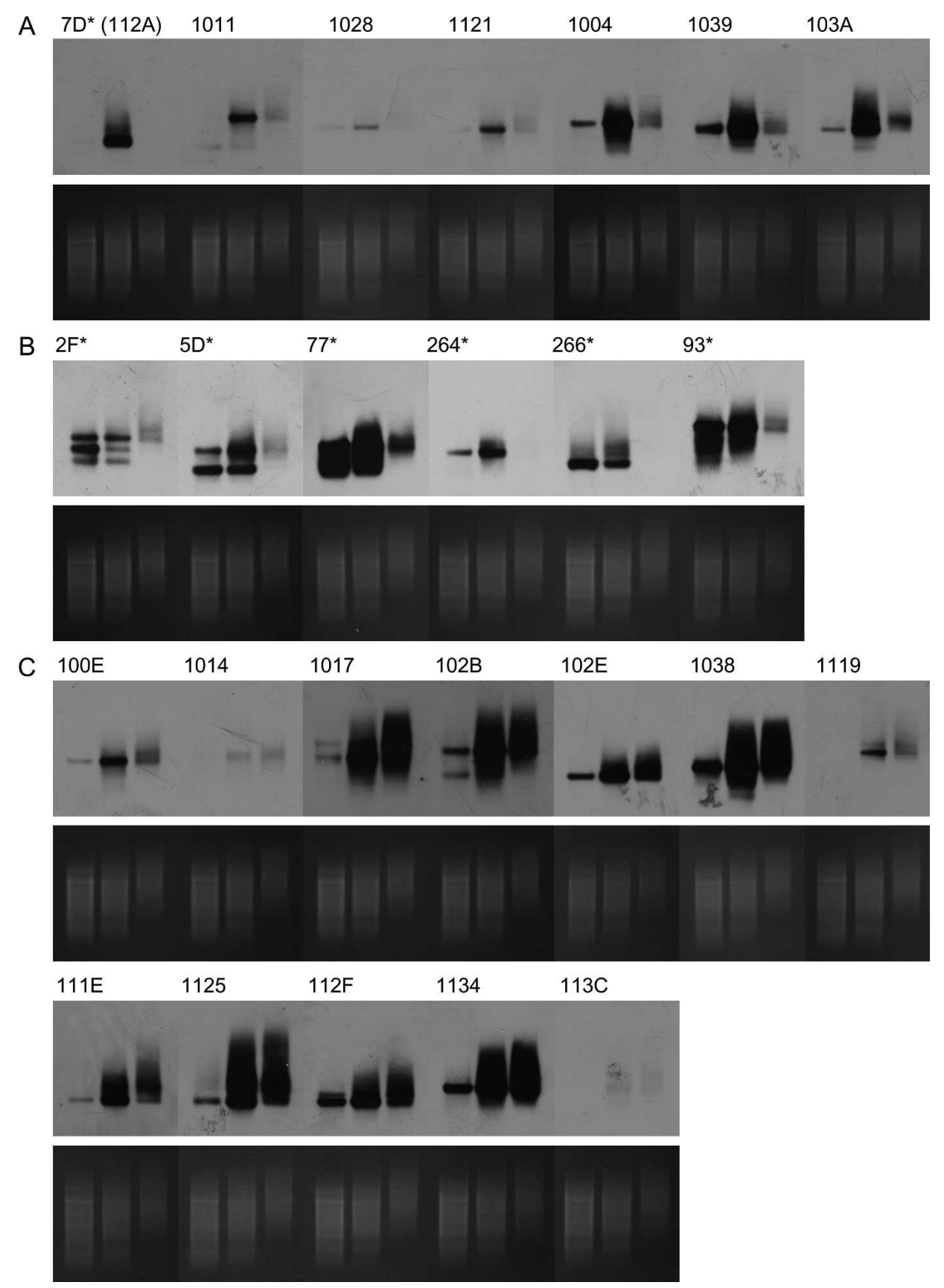

Fig. 1. Virtual northern blot hybridization analysis of suppression subtractive hybridization with mirror orientation selection (SSH/MOS) clones in paradormant, endodormant, and ecodormant lateral vegetative buds of japanese apricot. We analyzed the expression of selected seven clones from SSH/MOS library 1 (endodormant minus ecodormant) and 19 clones from SSH/MOS library 2 (endodormant minus paradormant). In each panel, left lane: paradormant buds (collected in June); center lane: endodormant buds (collected in October); right lane: ecodormant buds (collected in March). For each clone, the upper panel shows virtual northern blot bands, whereas the lower panel shows ethidium bromide-stained cDNAs as a loading control of the gel. Clone numbers correspond to those in Table 1. The classification of virtual northern blot banding patterns is as follows: (A) preferentially expressed in endodormant buds among three dormancy stages; (B) preferentially expressed in paradormant and endodormant buds among three dormancy stages; $(\mathbf{C})$ preferentially expressed in endodormant and ecodormant buds among three dormancy stages. Asterisks represent clones from SSH/MOS library 1 (see 
Table 1. List of clones in each suppression subtractive hybridization with mirror orientation selection (SSH/MOS) library. A total of seven and 19 clones were obtained from SSH/MOS library 1 and 2, respectively. A BLAST search of each clone was performed using two public databases [the DNA Data Bank of Japan (DDBJ) and the National Center for Biological Information (NCBI)]. The database-registered clone, which exhibited the strongest similarity to each SSH/MOS clone, is shown in the Hit ID column.

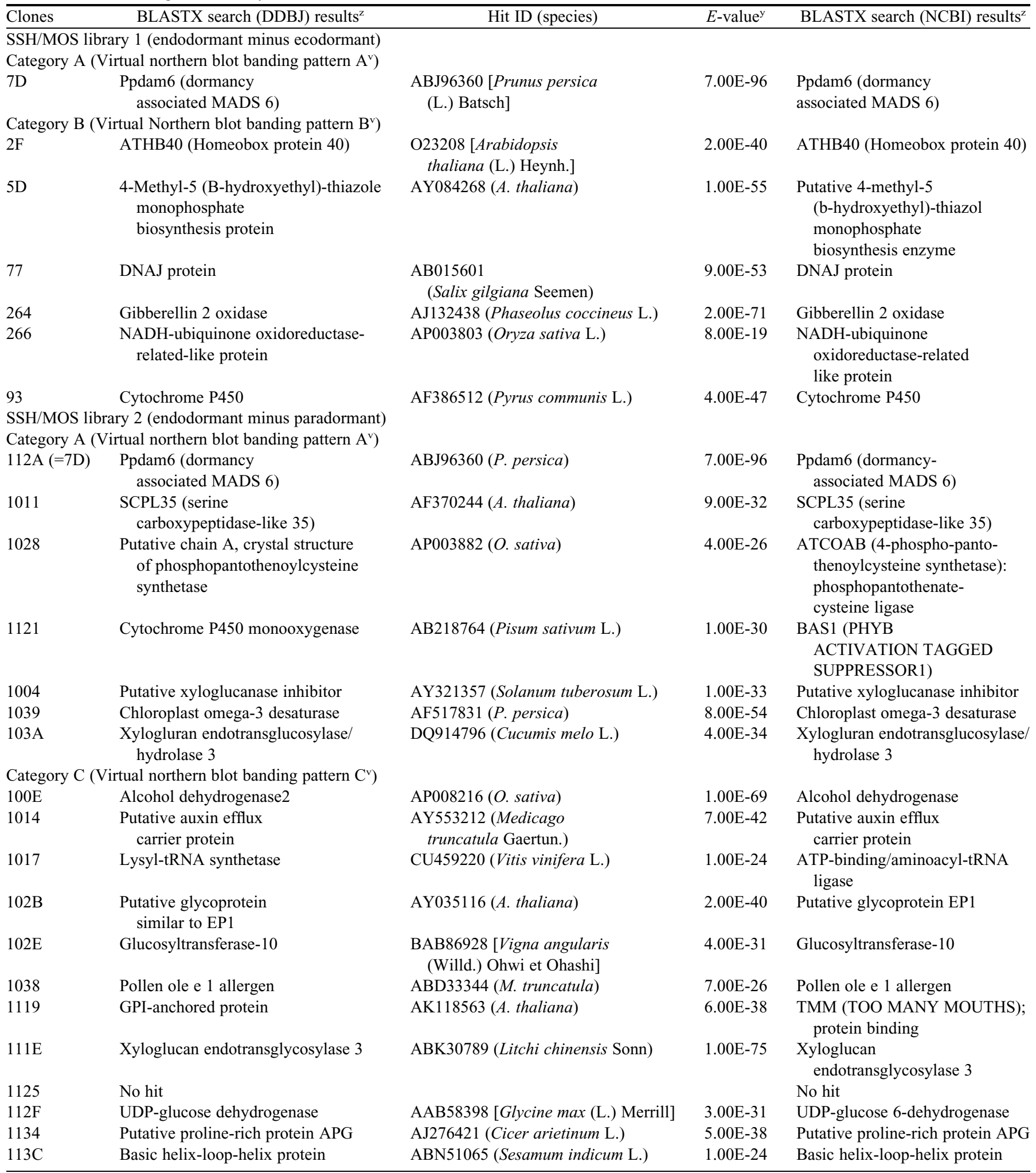

"The BLASTX searches were performed 1 May 2008.

${ }^{\text {y } T h e ~} E$-value from BLASTX, which exhibited the strongest similarity to annotated sequences.

${ }^{\mathrm{x}}$ The domain name retrieved by protein profiling database (pfam) search.

${ }^{\text {w } T h e ~ f u n c t i o n ~ o f ~ t h e ~ c l o n e s ~ w e r e ~ p r e d i c t e d ~ b a s e d ~ o n ~ t h e ~ B L A S T X ~ r e s u l t s ~ a n d ~ p f a m ~ r e s u l t s . ~}$

${ }^{\mathrm{v}}$ The classification of virtual northern blot banding patterns of the clones were shown and described in Fig. 1. 


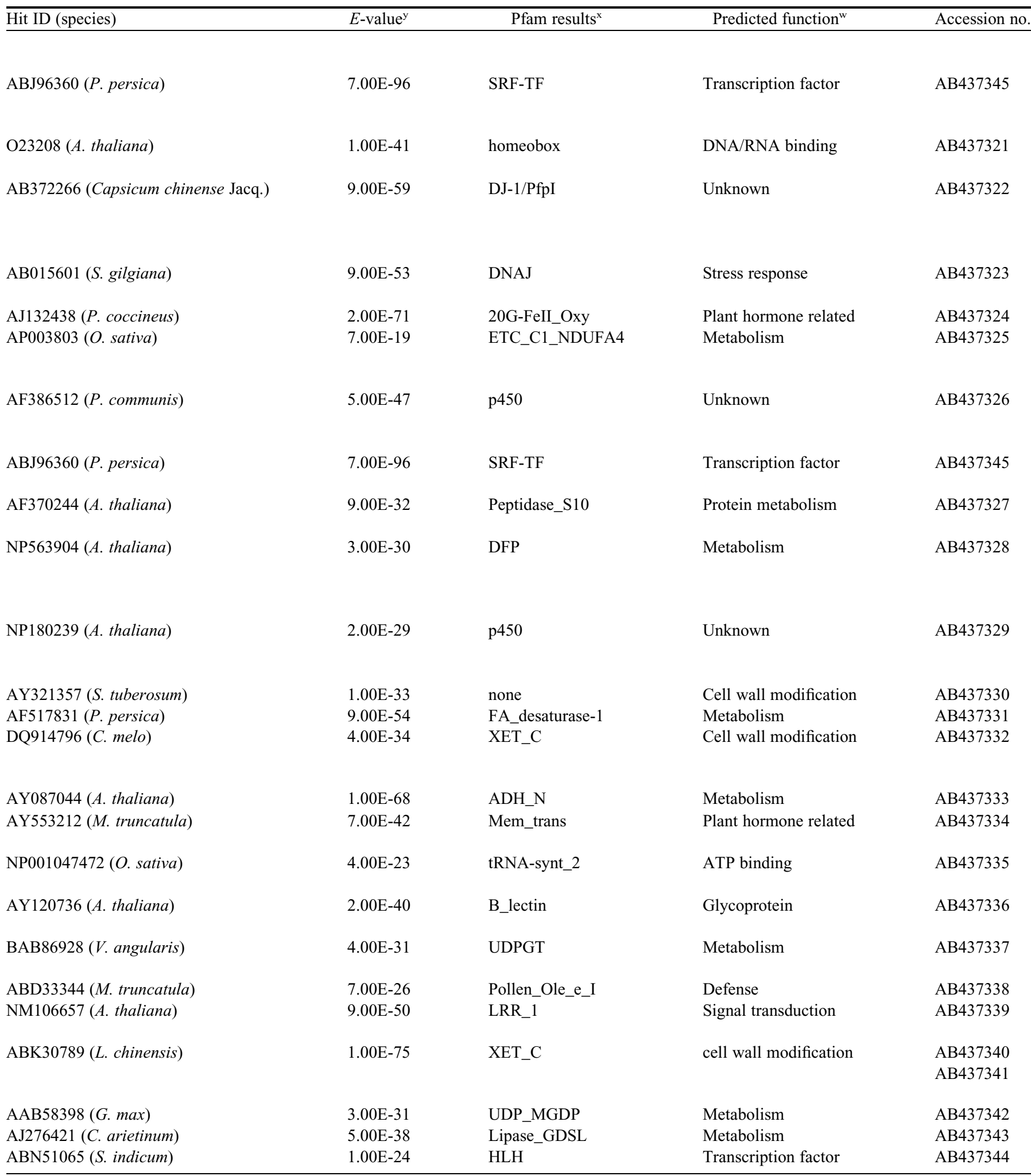

Druart et al., 2007; Eriksson and Moritz, 2002; Powell, 1987; Walker and Donoho, 1959; Walser et al., 1981) and seed dormancy (for review, see Finkelstein et al., 2008; Koornneef et al., 2002). This suggests a significant role of GA in the regulation of dormancy. A recent study of GA metabolism revealed that GA2ox deactivates the bioactive GAs, such as GA1 and GA4, via 2 $\beta$-hydroxylation (Thomas et al., 1999). The isolation of GA2ox in our SSH library 1 suggests that bioactive 
GAs are down-regulated in endodormant buds by accumulated GA2ox. If this is the case, fewer bioactive GAs may somehow be involved in endodormancy, although seasonal endogenous GA levels appear to be unrelated to dormancy status (Luna et al., 1990). Nevertheless, the upregulation of GA deactivators in endodormant buds does not conflict with previous studies that indicate the promotion of dormancy break by bioactive GA application and the requirement of bioactive GAs for seed germination.

DNAJ protein also showed down-regulation in ecodormant buds compared with endodormant buds. DNAJ protein provides stability to macromolecules like dehydrin, which accumulate in dormant buds (Arora et al., 1992; Artlip et al., 1997; Muthalif and Rowland, 1994; Yakovlev et al., 2008; Yamane et al., 2006). Although this accumulation was thought to be induced by cold acclimation (Muthalif and Rowland, 1994), the differential expression of dehydrin in winter buds between cultivars that have different chilling requirements for budbreak suggests that these molecules play a physiological role in flower bud development and dormancy (Artlip et al., 1997; Yakovlev et al., 2008; Yamane et al., 2006).

Many cell wall modification enzymes such as XTH and xyloglucanase inhibitor and secreted proteins such as glycoprotein and glycosyltransferase were included in SSH library 2 (Table 1). Most of them exhibited upregulation in endodormant buds compared with paradormant buds (Fig. 1). Previous studies have indicated that the lower symplastic cell-to-cell communication through plasmodesmata occurs in dormant buds of birch (Rinne et al., 2001). This suggests that cell wall and/or plasma membrane modification plays an important role in endodormancy regulation. Finally, in addition to a MADSbox gene, several signal transduction-associated factors such as basic helix-loop-helix protein, ATP-binding protein, and nucleotide-binding protein were identified in SSH libraries 1 and 2 (Table 1).

We isolated a common gene from both libraries, suggesting that some genes may be upregulated by endodormancy induction and down-regulated by endodormancy release. The genes that were expressed preferentially in endodormant buds compared with nonendodormant buds might function downstream of the endodormancy-regulation pathway after perception and transduction of the signals that induce endodormancy and endodormancy break. In our SSH libraries, seven clones showed strong preferential expression in endodormant buds compared with nonendodormant buds (Fig. 1A). Among these seven clones, no hybridization bands were detected in nonendodormant buds in clone 7D, suggesting that clone 7D shows endodormancy-associated expression. Clone 7D was found in both libraries and encodes a MADS-box transcription factor (Table 1, Fig. 1A). This clone was subjected to subsequent seasonal expression analysis related to seasonal dormancy status of the lateral buds of japanese apricot. Furthermore, its phylogenetic analysis was performed based on its full-length cDNA sequence.

AN $S V P / A G L$ 24-TYPE MADS-BOX GENE SHOWS ENDODORMANCY-ASSOCIATED EXPRESSION. Endodormancy status of the vegetative buds of 'Nanko' was evaluated using potgrown trees and cut branches. Bud burst was observed in June within $10 \mathrm{~d}$ after defoliation and decapitation in both tested potgrown trees. In July and August, bud burst was observed after 10 and $25 \mathrm{~d}$, respectively, in one of the two pot-grown trees, whereas bud burst was not observed after $28 \mathrm{~d}$ in the other tree, suggesting that the buds started to become endodormant in these months and that the endodormancy proceeded gradually. Bud burst was not observed in any buds in the branches collected from September to November, indicating that the buds are endodormant during these months. Then, $11 \%$ of the vegetative buds collected in December and January opened under favorable conditions. Finally, $71 \%$ and $94 \%$ of the vegetative buds collected in February and March, respectively, opened under favorable conditions. These results suggest that buds were released from endodormancy during December and January, and moved to the ecodormant stage in February.

The seasonal expression changes in clone 7D were monitored by RNA gel blot analysis (Fig. 2). In vegetative buds, no signal was detected in June when buds were not yet endodormant. The faint hybridization signal was detected in July and August when buds started to enter endodormancy. In September, October, and November, when buds were in deep endodormancy, strong hybridization signals were detected. During December and January when buds started to be released from endodormancy, faint hybridization signals were observed. In February and March when buds were in the ecodormant stage, no signal was detected. Taken together, these results clearly indicate that clone 7D was upregulated during the onset of endodormancy and down-regulated during endodormancy release.

The full-length cDNA encoding clone 7D was obtained from the endodormant bud cDNA library. Because the deduced amino acid sequence showed the highest sequence identity (91.7\%) with Ppdam6, this clone was named Pmdam6 (Prunus mume dormancy-associated MADS6). The amino acid sequence of Pmdam6 was aligned with 38 known MIKC-type MADS-box genes from arabidopsis to construct a phylogenetic tree. The resulting phylogenetic tree demonstrated that Pmdam6 was classified in the StMADS11 (SVP/AGL24) superclade (Pařenicová et al., 2003; Laseberg et al., 2006), together with SHORT VEGETATIVE PHASE (SVP) (Hartmann et al., 2000) and AGAMOUS-LIKE24 (AGL24) (Michaels et al., 2003) from arabidopsis (Fig. 3). In arabidopsis, $S V P$ and $A G L 24$ were primarily expressed in vegetative tissues and are phylogenetically closely related to each other (Pařenicová et al., 2003). However, functional analysis indicated that they have opposite effects in the regulation of floral transition. Whereas $S V P$ acts as a repressor of floral transition (Hartmann et al., 2000), AGL24 promotes flowering. Recently, woody plant homologs of arabidopsis flowering-related genes, such as $C O$ and FT homologs, were found to be involved in endodormancy (Böhlenius et al., 2006). Our finding that a homolog of another flowering-related gene, $S V P / A G L 24$, is putatively related to endodormancy in japanese apricot, in addition to the recent finding that SVP homologs in peach are associated with terminal bud formation (Bielenberg et al., 2008), suggests the significant roles of homologs of flowering-related genes of arabidopsis in bud endodormancy of woody plants.

In peach, MADS-box genes including Ppdam6 were located in the $E V G$ locus. Evg peach is a naturally occurring mutant unable to cease terminal meristem growth or form terminal buds (Bielenberg et al., 2004; Rodriguez et al., 1994; Wang et al., 2002). The MADS-box genes were expressed in terminal buds of the wild type, whereas none were expressed in the terminal meristem region of the evg mutant, suggesting that they are candidate genes for the regulation of growth cessation and 


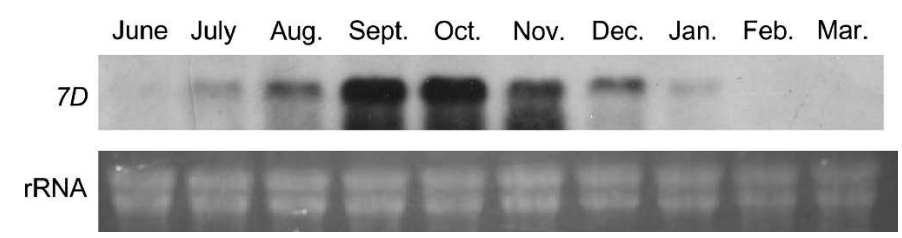

Fig. 2. RNA blot analysis of suppression subtractive hybridization with mirror orientation selection clone 7D in seasonal lateral vegetative buds of japanese apricot 'Nanko'. Total RNA (5 $\mu \mathrm{g}$ per lane) extracted from monthly collected vegetative buds was used and hybridized with DIG-labeled 7D probe. The collection months are shown above the lanes. The upper panel shows the hybridization bands, whereas the lower panel shows the ethidium bromidestained rRNA bands as a loading control for the gel. The endodormancy status of each collection month was investigated and described in the text.

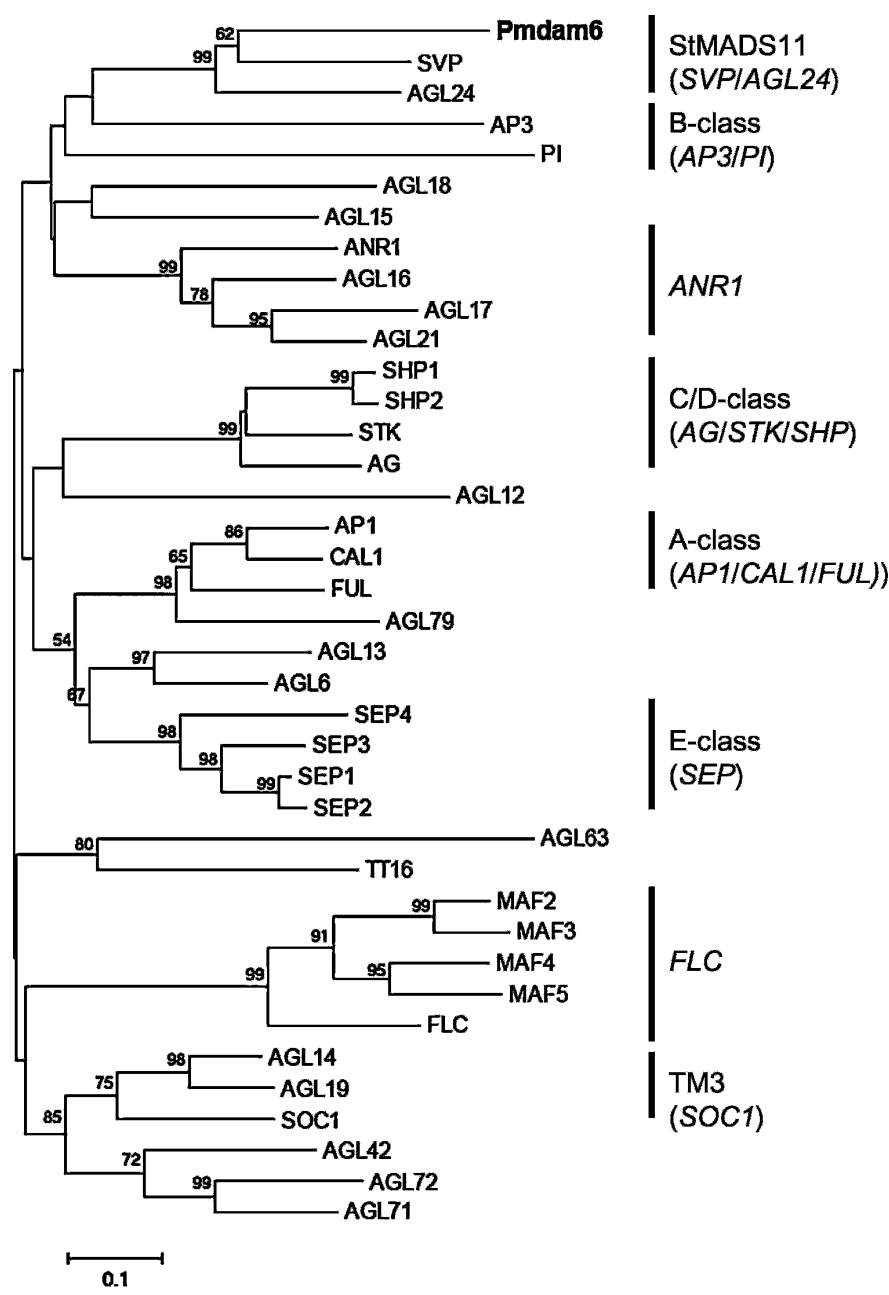

Fig. 3. The phylogenic tree of Pmdam6 and arabidopsis MIKC-type MADS-box sequences. After their full-length deduced amino acid sequences were aligned using CLUSTAL X software, the phylogenetic tree was constructed by the neighbor-joining method. Branches with more than $50 \%$ bootstrap support are shown.

terminal bud formation in peach (Bielenberg et al., 2004, 2008). However, the endodormancy status of lateral buds of the evg mutant or the expression of MADS-box genes in lateral buds in wild types and mutants has yet to be investigated. We focused on lateral bud endodormancy in japanese apricot and isolated Pmdam6, an ortholog of Ppdam6, as a strong candidate for endodormancy regulation from among $>1500$ SSH clones. Its endodormancy-associated expression in lateral buds suggests that Pmdam6 might be involved in endodormancy induction and endodormancy release of lateral buds in japanese apricot. This implies that Pmdam6 might function as an internal suppressor gene to delay or inhibit bud growth under conditions favorable for bud burst when none of the external inhibitory effects such as apical dominance or inferior environmental conditions exist. Interestingly, gradual down-regulation of the SVP-type MADS-box gene was also observed during the dormancy release of raspberry buds (Mazzitelli et al., 2007). This suggests that SVP-type MADS-box genes are involved in endodormancy of deciduous fruit tree species. Extensive expression analyses with special references to chilling exposure as well as functional analyses of this gene are under way to address the possible involvement of Pmdam6 in lateral bud endodormancy induction and endodormancy release in japanese apricot.

\section{Literature Cited}

Arora, R., M.E. Wisniewski, and R. Scorza. 1992. Cold acclimation in genetically related (sibling) deciduous and evergreen peach [Prunus persica (L.) Batch] I. Seasonal changes in cold hardiness and polypeptides of bark and xylem tissues. Plant Physiol. 99:1562-1568.

Artlip, T.S., A.M. Callahan, C.L. Bassett, and M.E. Wisniewski. 1997. Seasonal expression of a dehydrin gene in sibling deciduous and evergreen genotypes of peach [Prunus persica (L.) Batsch]. Plant Mol. Biol. 33:61-70.

Bielenberg, D.G., Y. Wang, S. Fan, G.L. Reighard, R. Scorza, and A.G. Abbott. 2004. A deletion affecting several gene candidates is present in the evergrowing peach mutant. J. Hered. 95:436-444.

Bielenberg, D.G., Y.E. Wang, L. Zhigang, T. Zhebentyayeva, S. Fan, G.L. Reighard, R. Scorza, and A.G. Abbott. 2008. Sequencing and annotation of the evergrowing locus in peach [Prunus persica (L.) Batsch] reveals a cluster of six MADS-box transcription factors as candidate genes for regulation of terminal bud formation. Tree Genet. Genomics 4:495-507.

Böhlenius, H., T. Huang, L. Charbonnel-Campaa, A.M. Brunner, S. Jansson, S.H. Strauss, and O. Nilsson. 2006. CO/FT regulatory module controls timing of flowering and seasonal growth cessation in trees. Science 312:1040-1043.

Crabbe, J. and P. Barnola. 1996. A new conceptual approach to bud dormancy in woody plants, p. 83-113. In: G.A. Lang (ed.). Plant dormancy: Physiology, biochemistry and molecular biology. CAB International, Wallingford, UK.

Druart, N., A. Johansson, K. Baba, J. Schrader, A. Sjodin, R.R. Bhalerao, L. Resman, J. Trygg, T. Moritz, and R.P. Bhalerao. 2007. Environmental and hormonal regulation of the activitydormancy cycle in the cambial meristem involves stage specific modulation of transcriptional and metabolic networks. Plant J. 50:557-573.

Eriksson, M.E. and T. Moritz. 2002. Daylength and spatial expression of a gibberellin 20-oxidase isolated from hybrid aspen (Populus tremula L. $\times$ P. tremuloides Michx.). Planta 214:920-930.

Faust, M., A. Erez, L.J. Rowland, S.Y. Wang, and H.A. Norman. 1997. Bud dormancy in perennial fruit trees: Physiological basis for dormancy induction, maintenance, and release. HortScience 32: 623-629.

Finkelstein, R., W. Reeves, T. Ariizumi, and C. Steber. 2008. Molecular aspects of seed dormancy. Annu. Rev. Plant Biol. 59: 387-415.

Hartmann, U., S. Hormann, K. Nettesheim, E. Wisman, H. Saedler, and P. Huijser. 2000. Molecular cloning of SVP: A negative regulator of the floral transition in Arabidopsis. Plant J. 21:351-360.

Horvath, D.P., J.V. Anderson, W.S. Chao, and M.E. Foley. 2003. Knowing when to grow: Signals regulating bud dormancy. Trends Plant Sci. 8:534-540. 
Jia, Y., J.V. Anderson, D.P. Horvath, Y.-Q. Gu, R.G. Lym, and W.S. Chao. 2006. Subtractive cDNA libraries identify differentially expressed genes in dormant and growing buds of leafy spurge (Euphorbia esula). Plant Mol. Biol. 61:329-344.

Koornneef, M., L. Bentsink, and H. Hilhorst. 2002. Seed dormancy and germination. Curr. Opin. Plant Biol. 5:33-36.

Lang, G.A. 1987. Dormancy: A new universal terminology. HortScience 22:817-820.

Laseberg, C.H., A. Li, H. Kang, M. Duval, and L. Mao. 2006. Genomewide analysis of the MADS-box gene family in Populus trichocarpa (Torr \& Gray). Gene 378:84-94.

Luna, V., E. Lorenzo, H. Reinoso, M.C. Tordable, G. Abdala, R.P. Pharis, and R. Bottini. 1990. Dormancy in peach (Prunus persica L.) flower buds. I. Floral morphogenesis and endogenous gibberellins at the end of the dormancy period. Plant Physiol. 93:244-246.

Mazzitelli, L., R.D. Hancock, S. Haupt, P.G. Walker, S.D.A. Pont, J. McNicol, L. Cardle, J. Morris, R. Viola, R. Brennan, P.E. Hedley, and M.A. Taylor. 2007. Coordinated gene expression during phases of dormancy release in raspberry (Rubus idaeus L.) buds. J. Expt. Bot. 58:1035-1045.

Michaels, S.D., G. Ditta, C. Gustafson-Brown, S. Pelaz, M. Yanofsky, and R.M. Amasino. 2003. AGL24 acts as a promoter of flowering in Arabidopsis and is positively regulated by vernalization. Plant $\mathrm{J}$. 33:867-874.

Miyahata, R. and K. Tomita. 1982. Studies on methods for stabilizing japanese apricot bearing. I. Effect of gibberellin on flowering of japanese apricot (Prunus mume Sieb. et Zucc.). Fukui Prefecture Hort. Res. Ctr. Bul. 1, (In Japanese).

Muthalif, M.M. and L.J. Rowland. 1994. Identification of dehydrinlike proteins responsive to chilling in floral buds of blueberry (Vaccinium, section Cyanococcus). Plant Physiol. 104:1439-1447.

Pacey-Miller, T., K. Scott, E. Ablett, S. Tingery, A. Ching, and R. Henry. 2003. Genes associated with the end of dormancy in grapes. Functional Integrated Genomics 3:144-152.

Pařenicová, L., S. de Folter, M. Kieffer, D.S. Horner, C. Favalli, J. Busscher, H.E. Cook, R.M. Ingram, M.M. Kater, B. Davies, G.C. Angenent, and L. Colombo. 2003. Molecular and phylogenetic analyses of the complete MADS-box transcription factor family in Arabidopsis: New openings to the MADS world. Plant Cell 15:1538-1551.

Powell, L.E. 1987. Hormonal aspects of bud and seedling dormancy in temperate-zone woody plants. HortScience 22:845-850.

Rebrikov, D.V., O.V. Britanova, N.G. Gurskaya, K.A. Lukyanov, V.S. Tarabykin, and S.A. Lukyanov. 2000. Mirror orientation selection (MOS): A method for eliminating false-positive clones from libraries generated by suppression subtractive hybridization. Nucleic Acids Res. 28:E90.

Rinne, P., P.M. Kaikuranta, and C. van der Schoot. 2001. The shoot apical meristem restores its symplasmic organization during chillinginduced release from dormancy. Plant J. 26:249-264.

Rodriguez, J., W.B. Sherman, R. Scorza, M. Wisniewski, and W.R. Okie. 1994. Evergreen peach, its inheritance and dormancy behavior. J. Amer. Soc. Hort. Sci. 119:789-792.
Rohde, A. and R.P. Bhalerao. 2007. Plant dormancy in the perennial context. Trends Plant Sci. 12:217-223.

Rohde, A., E. Prinsen, R. De Rycke, G. Engler, M. van Montagu, and W. Boerjan. 2002. PtABI3 impinges on the growth and differentiation of embryonic leaves during bud set in poplar. Plant Cell 14: $1885-1901$

Rohde, A., T. Ruttink, V. Hostyn, L. Sterck, K.V. Driessche, and W. Boerjan. 2007. Gene expression during the induction, maintenance, and release of dormancy in apical buds of poplar. J. Expt. Bot. 58: 4047-4060.

Ruttink, T., M. Arend, K. Morreel, V. Storme, S. Rombauts, J. Fromm, R.P. Bhalerao, W. Boerjan, and A. Rohde. 2007. A molecular timetable for apical bud formation and dormancy induction in poplar. Plant Cell 19:2370-2390.

Sugiura, T., H. Kuroda, and H. Sugiura. 2007. Influence of the current state of global warming on fruit tree growth in Japan. Hort. Res. (Japan) 6:257-263 (In Japanese with English summary).

Takamatsu, Y., T. Kitagawa, T. Takebayashi, and N. Utsunomiya. 2004. Scanning electron microscopy of development of axillary buds in 'Nankoh' japanese apricot (growth regulation). Hort. Res. (Japan) 3:409-413 (In Japanese with English summary).

Tamura, K., J. Dudley, M. Nei, and S. Kumar. 2007. MEGA4: Molecular evolutionary genetic analysis (MEGA) software version 4.0. Mol. Biol. Evol. 24:1596-1599.

Tao, R., H. Yamane, A. Sugiura, H. Murayama, H. Sassa, and H. Mori. 1999. Molecular characterization of $S$-alleles through identification, characterization and cDNA cloning for S-RNases in sweet cherry. J. Amer. Soc. Hort. Sci. 124:224-233.

Thomas, S.G., A.L. Phillips, and P. Hedden. 1999. Molecular cloning and functional expression of gibberellin 2-oxidases, multifunctional enzymes involved in gibberellin deactivation. Proc. Natl. Acad. Sci. USA 13:4698-4703.

Walker, D.R. and C.W. Donoho. 1959. Further studies on the effect of gibberellic acid on breaking the rest period of young peach and apple trees. Proc. Amer. Soc. Hort. Sci. 74:87-92.

Walser, R.H., D.R. Walker, and S.D. Seeley. 1981. Effect of temperature, fall defoliation, and gibberellic acid on the rest period of peach leaf buds. J. Amer. Soc. Hort. Sci. 106:9194.

Wang, Y., L.L. Georgi, G.L. Reighard, R. Scorza, and A.G. Abbott. 2002. Genetic mapping of the evergrowing gene in peach [Prunus persica (L.) Batsch]. J. Hered. 93:352-358.

Yakovlev, I.A., D.K.A. Asante, C.G. Fossdal, J. Partanen, O. Junttila, and Ø. Johnsen. 2008. Dehydrins expression related to timing of bud burst in norway spruce. 1 July 2008. <http://www.springerlink.com/ content/n4706207h43228j4/fulltext.html $>$.

Yamane, H., Y. Kashiwa, E. Kakehi, K. Yonemori, H. Mori, K. Hayashi, K. Iwamoto, R. Tao, and I. Kataoka. 2006. Differential expression of dehydrin in flower buds of two japanese apricot cultivars requiring different chilling requirements for bud break. Tree Tree Physiol. 26:1559-1563. 